\title{
Lateral Lymph Node Dissection With the Focus on Indications, Functional Outcomes, and Minimally Invasive Surgery
}

\author{
Min Jung Kim ${ }^{1,2}$, Jae Hwan $\mathrm{Oh}^{3}$ \\ ${ }^{1}$ Department of Surgery, Seoul National University College of Medicine, Seoul; ${ }^{2}$ Cancer Research Institute, Seoul National University, Seoul; \\ ${ }^{3}$ Center for Colorectal Cancer, Research Institute and Hospital, National Cancer Center, Goyang, Korea
}

The lateral lymph node dissection (LLND) is still a subject of great debate as to the appropriate treatment for patients with mid to low advanced rectal cancer. The guidelines of the Japanese Society for Cancer of the Colon and Rectum recommend a LLND for patients with T3/4 rectal cancer below the peritoneal reflection. However, in most Western countries, a routine LLND is not recommended unless a node or nodes are clinically suspicious for metastasis. Even after preoperative chemoradiotherapy (CRT), an $8 \%$ to $12 \%$ lateral pelvic recurrence was noted. The size of the lateral lymph node and responsiveness to preoperative CRT should be the main factors for selecting appropriate patients to undergo a LLND. In addition, from the recent literature, a laparoscopic LLND is safe and oncologically feasible and might have some advantages in short-term outcomes.

Keywords: Rectal neoplasms; Lymph Nodes; Chemoradiotherapy

\section{INTRODUCTION}

The incidence of lateral pelvic lymph node metastasis has been estimated to range from $11 \%$ to $22 \%$ in patients with $\mathrm{T} 3 / 4$ rectal cancer below the peritoneal reflection [1-5]. Although the therapeutic benefit of lateral lymph node dissection (LLND) is reported to be higher than that of lymph node dissection in the area of either the superior rectal or the inferior mesenteric artery [6], the strategy for the use of a LLND has varied among nations and surgeons because of different views concerning lateral pelvic lymph node metastasis. In the view of Western countries, preoperative chemoradiotherapy (CRT) followed by a total mesorectal

Received: October 16, 2018 • Accepted: October 26, 2018

Correspondence to: Jae Hwan Oh, M.D.

Center for Colorectal Cancer, Research Institute and Hospital, National

Cancer Center, 323 Ilsan-ro, Ilsandong-gu, Goyang 10408, Korea

Tel: +82-31-920-1637, Fax: +82-31-920-1148

E-mail: jayoh@ncc.re.kr

ORCID code: https://orcid.org/0000-0002-5883-5815

(C) 2018 The Korean Society of Coloproctology

This is an open-access article distributed under the terms of the Creative Commons Attribution NonCommercial License (http://creativecommons.org/licenses/by-nc/4.0) which permits unrestricted noncommercial use, distribution, and reproduction in any medium, provided the original work is properly cited. excision (TME) has been the standard treatment for patients with locally advanced rectal cancers, and metastasis to extramesorectal lymph nodes, except the lymph nodes in the area of the internal iliac artery, has been regarded as a systematic disease that requires systemic chemotherapy $[7,8]$. However, in recent reports, preoperative CRT with a TME could not completely render the lateral lymph node benign, so the remnant metastatic lymph node could still cause local pelvic recurrence $[9,10]$. In Japan, surgeons have been using the LLND since the 1970s to decrease local recurrence and improve prognosis [11], and the procedure has progressed from a routine en bloc extended pelvic lymphadenectomy to autonomic nerve-preserving surgery; furthermore, selective application of the procedure has reduced functional compromise and increased its oncologic efficacy [12-15].

In this paper, we will review the indications for selective LLND in the era of preoperative CRT because preoperative evaluation has progressed due to the adoption of high-resolution rectal magnetic resonance imaging (MRI) and to the fact that more reliable imaging of the lateral pelvic lymph node has become possible. We will also review the recent literature on the LLND from the perspective of functional outcomes and the setting for minimally invasive surgery. 


\section{INDICATIONS FOR A LATERAL PELVIC LYMPH NODE DISSECTION}

Recently, interest in LLND for treating patients with locally advanced rectal cancer has been growing, but the optimal indications for LLND have not yet been established. In Japan, the guidelines of the Japanese Society for Cancer of the Colon and Rectum (JSCCR) recommend that a bilateral LLND be performed in patients whose lower tumor border is located distal to the peritoneal reflection and whose cancer has invaded beyond the muscularis propria. The LLND lowered the risk of intrapelvic recurrence by $50 \%$, and the 5 -year survival rate improved by $8 \%$ to $9 \%$ without preoperative CRT [16].

On the other hand, the National Comprehensive Cancer Network does not recommend an extended lymphadenectomy unless lateral lymph nodes are clinically suspicious, and the detailed indications for LLND have not been clearly defined. However, researchers have recognized that preoperative CRT with TME might not be sufficient to prevent lateral local recurrences $[9,10]$. Kim et al. [10] noted that $83 \%$ of patients with locoregional recurrence had lateral pelvic recurrence even after preoperative CRT and a curative proctectomy. Kusters et al. [9] reported a 5-year lateral local recurrence rate of $11.8 \%$ in the Western population, and patients with lateral nodes with malignant features had a lateral local recurrence rate $(20.9 \%)$ twice as high as those without malignant-looking nodes (10.3\%).

The size of the lateral LN before treatment has been reported to be the main factor for predicting lateral pelvic recurrences and metastasis to lymph nodes. The cutoff size of lateral nodes has been reported to vary from 5 to $8 \mathrm{~mm}$ [17-20], but a recent JSCCR report has identified a 5-mm cutoff on the short axis as being optimal for detecting metastatic nodes. The rate of lateral pelvic recurrence increases as the size of the lateral $\mathrm{LN}$ increases [10], and when the diameter of the largest lateral $\mathrm{LN}$ is in the range from 5 to $10 \mathrm{~mm}$ or more than $10 \mathrm{~mm}$, the incidence of lateral spread is $20 \%$ or $36.7 \%$, respectively [6]. Based on MRI imaging, JSCCR studied the optimum cutoff for lateral lymph node size to identify metastatic nodes; it found that a $5-\mathrm{mm}$ cutoff on the short-axis was superior to a 10 -mm cutoff [18]. It also reported that compared with other factors, including histopathological grade, perirectal nodes, and distant metastasis, an enlarged pelvic node status with a short axis $\geq 5 \mathrm{~mm}$ on MRI was the most important risk factor for metastasis [21].

After administration of preoperative CRT, the responsiveness, that is, the change in LN size, may be considered as another factor indicating the need for LLND. Oh et al. [22] reported that unlike responsive lymph nodes, persistent lateral lymph nodes greater than $5 \mathrm{~mm}$ in size after CRT were significantly associated with residual tumor metastasis. Kim et al. [23] divided patients into three groups: group I (no suspicious lateral LNs), i.e., lateral $\mathrm{LN}<5 \mathrm{~mm}$ pre- and post-CRT; group II (responsive lateral LN), lateral pelvic node $\geq 5 \mathrm{~mm}$ pre-CRT, but $<5 \mathrm{~mm}$ post-CRT; and group III (per- sistent lateral pelvic node), lateral pelvic node $\geq 5 \mathrm{~mm}$ pre- and post-CRT. Group III had significantly poorer lateral pelvic node recurrence-free survival than groups I and II. In summary, the size of the lateral LN and the responsiveness to preoperative CRT might be the main factors for considering LLND. Further research is needed to define the optimal indications for LLND.

\section{FUNCTIONAL OUTCOMES AFTER A LATERAL LYMPH NODE DISSECTION}

The functional compromise after LLND for patients with rectal cancer has been a major concern (Table 1). The operative extent of LLND involves inevitably some injury to the vessels and nerves in the pelvic sidewall, and the sexual and voiding functions are usually decreased after LLND. In early reports from Japan, LLND included an extended systematic lymphadenectomy, which means para-aortic and paracaval lymphatic dissection from the left renal vein to the aortic bifurcation along the adventitial layers of the inferior vena cave and abdominal aorta [24]. This procedure accompanied inevitable functional deteriorations $[25,26]$ and increased incidences of urine-voiding failure (39.4\% after the extended lymphadenectomy vs. $8.8 \%$ after the conventional lymphadenectomy) and sexual impotency ( $76 \%$ vs. $37.5 \%$ ). In the metaanalysis, the extended lymphadenectomy showed a 3.7 times higher risk of urinary dysfunction and a 2.08 times higher risk of urinary retention [8].

However, the literature on a nerve-preserving lymphadenectomy demonstrates that autonomic nerve preservation offers advantages in maintaining urinary and sexual functions [13, 27-30]. In the recent Japan Clinical Oncology Group 0212 trial, postoperative urinary dysfunction developed in 59\% of patients who underwent LLLD, and sexual dysfunction occurred in $79 \%$ of such patients; these results were not significantly different from those for the TME-alone group [31, 32]. The degree of dysfunction has been reported to be related to the extent of the lymphadenectomy and autonomic nerve preservation [29], so the oncological benefits and functional deterioration should be balanced.

\section{LAPAROSCOPIC LATERAL LYMPH NODE DISSECTION}

Laparoscopic LLND with its enhanced visualization may be the next promising approach and may not only provide a survival benefit but also minimize bleeding and postoperative complications. Laparoscopic surgery provides a high-definition, magnified, clear view, and recent advances in 3-dimensional laparoscopy and near-infrared cameras have enhanced the efficiencies of surgeries, such as LLND, that need a multidirectional approach.

A single-arm study reported the technical feasibility of laparoscopic LLND. In 2011, Konishi et al. [33] treated 14 patients laparoscopically, and the median amount of bleeding and operative time were $25 \mathrm{~mL}$ (range, 5-1,190 mL) and 413 minutes (range, 
Table 1. Summary table of literature review regarding postoperative functional outcomes of cases with lateral lymph node dissection

\begin{tabular}{lll}
\hline Study & Function evaluated & \multicolumn{1}{c}{ Postoperative functional results of cases with lateral lymph node dissection } \\
\hline Sugihara et al. [30] (1996) & Sexual function & $29.6 \%$ Did not maintain male sexual function postoperatively \\
Matsuoka et al. [25] (2001) & Urinary function & $86 \%$ Showed dysuria \\
& & $40 \%$ Showed urinary incontinence \\
& & $54 \%$ Showed change in bladder sensation \\
& & $25 \%$ Needed CiC for more than 3 years postoperatively \\
Maeda et al. [28] (2003) & Urinary function & $15 \%$ Showed minor disturbance \\
& Sexual function & $27 \%$ Showed partial or total impotency \\
Col et al. [26] (2005) & Urinary function & $58 \%$ Showed urinary incontinence \\
Kyo et al. [27] (2006) & Urinary function & $16 \%$ Showed urinary retention \\
& Sexual function & $13.3 \%$ Showed difficulty in emptying bladder \\
& & $50 \%$ Showed decreased sexual activity \\
Saito et al. [31] (2016) & $50 \%$ Suffered from erectile dysfunction \\
Ito et al. [32] (2018) & $90 \%$ Suffered from ejaculatory dysfunction \\
\hline
\end{tabular}

$\mathrm{CIC}$, clean intermittent catherization.

277-596 minutes), respectively. In the similar period, 16 patients underwent laparoscopic LLLND in Korea without conversion, and the mean blood loss was only $188 \mathrm{~mL}$ [34]. Furuhata et al. [35] reported the technical and oncologic safety of laparoscopic LLND without open conversion; no recurrences were detected during the mean 24-month follow-up.

Studies comparing laparoscopic versus open TME with LLND have reported laparoscopic surgery to be feasible and to have benefits such as lower blood loss and shorter hospital stay over open LLND. Ogura et al. [36] analyzed data from 107 patients and found the rates of major complications to be similar between the 2 groups ( $9.3 \%$ vs. $5.5 \%, \mathrm{P}=0.188)$. In another study with patient matching, laparoscopic surgery resulted in less blood loss (193 $\mathrm{mL}$ vs. $722 \mathrm{~mL})$, similar postoperative complication rates $(35.8 \%$ vs. $43.6 \%$ ), and long-term survival [37]. A third study also reported similar results, including less blood loss, shorter hospital stays, and similar complication and survival rates [38].

In case of local recurrence after TME, adhesions make surgery a technically demanding procedure, but in this case, laparoscopic salvage LLND showed acceptable complications [39]. Therefore, although evidence for the feasibility and safety of laparoscopic LLND is limited, that procedure should be considered to be safe and oncologically feasible; in addition, it may have some advantages for short-term outcomes.

Robotic surgery for LLND was also feasible in terms of shortterm and long-term oncologic outcomes. In 50 cases, Kagawa et al. [40] demonstrated that robotic procedure resulted in minimal blood loss and no conversion to open or laparoscopic surgery. Ya- maguchi [41] reported that the overall survival and local relapsefree survival rate was similar between open and robotic LLND. Other small reports showed the feasibility of robotic LLND [42-44].

\section{CONCLUSIONS}

Over the past 30 years, the sexual and urinary functional outcomes after a LLND have improved due to autonomic nerve preservation and to advances in imaging modalities, such as high-resolution MRI, that enable more selective application of a LLND. Even with preoperative CRT, local pelvic recurrence is not preventable in about $5 \%$ to $10 \%$ of patients; nevertheless, a LLND may further decrease the local recurrence rate in patients with enlarged pelvic lymph nodes. With future study, we may be able to narrow the indications, in combination with the size of the lateral $\mathrm{LN}$ and the response to preoperative CRT, and minimize overtreatment. In addition, we need further study on the short-term advantages of using minimally invasive surgery for a LLND.

\section{CONFLICT OF INTEREST}

No potential conflict of interest relevant to this article was reported.

\section{ACKNOWLEDGMENTS}

This study was supported by a grant from National Cancer Center (grant number: 1810181-1). 


\section{REFERENCES}

1. Ueno M, Oya M, Azekura K, Yamaguchi T, Muto T. Incidence and prognostic significance of lateral lymph node metastasis in patients with advanced low rectal cancer. Br J Surg 2005;92:756-63.

2. Sugihara K, Kobayashi H, Kato T, Mori T, Mochizuki H, Kameo$\mathrm{ka} \mathrm{S}$, et al. Indication and benefit of pelvic sidewall dissection for rectal cancer. Dis Colon Rectum 2006;49:1663-72.

3. Kobayashi H, Mochizuki H, Kato T, Mori T, Kameoka S, Shirouzu $\mathrm{K}$, et al. Outcomes of surgery alone for lower rectal cancer with and without pelvic sidewall dissection. Dis Colon Rectum 2009; 52:567-76.

4. Fujita S, Yamamoto S, Akasu T, Moriya Y. Risk factors of lateral pelvic lymph node metastasis in advanced rectal cancer. Int J Colorectal Dis 2009;24:1085-90.

5. Akiyoshi T, Watanabe T, Miyata S, Kotake K, Muto T, Sugihara K, et al. Results of a Japanese nationwide multi-institutional study on lateral pelvic lymph node metastasis in low rectal cancer: is it regional or distant disease? Ann Surg 2012;255:1129-34.

6. Ueno H, Mochizuki H, Hashiguchi Y, Ishiguro M, Miyoshi M, Kajiwara Y, et al. Potential prognostic benefit of lateral pelvic node dissection for rectal cancer located below the peritoneal reflection. Ann Surg 2007;245:80-7.

7. National Comprehensive Cancer Network. Recent Updates to NCCN Clinical Practice Guidelines in Oncology (NCCN Guidelines) [Internet]. Fort Wathington (PA): National Comprehensive Cancer Network; c2018 [cited 2018 Sep 3]. Available from: https:// www.nccn.org/professionals/physician_gls/recently_updated. aspx.

8. Georgiou P, Tan E, Gouvas N, Antoniou A, Brown G, Nicholls RJ, et al. Extended lymphadenectomy versus conventional surgery for rectal cancer: a meta-analysis. Lancet Oncol 2009;10:1053-62.

9. Kusters M, Slater A, Muirhead R, Hompes R, Guy RJ, Jones OM, et al. What to do with lateral nodal disease in low locally advanced rectal cancer? A call for further reflection and research. Dis Colon Rectum 2017;60:577-85.

10. Kim TH, Jeong SY, Choi DH, Kim DY, Jung KH, Moon SH, et al. Lateral lymph node metastasis is a major cause of locoregional recurrence in rectal cancer treated with preoperative chemoradiotherapy and curative resection. Ann Surg Oncol 2008;15:72937.

11. Moriya Y, Sugihara K, Akasu T, Fujita S. Importance of extended lymphadenectomy with lateral node dissection for advanced lower rectal cancer. World J Surg 1997;21:728-32.

12. Konishi T, Watanabe T, Nagawa H, Oya M, Ueno M, Kuroyanagi $\mathrm{H}$, et al. Preoperative chemoradiation and extended pelvic lymphadenectomy for rectal cancer: two distinct principles. World J Gastrointest Surg 2010;2:95-100.

13. Moriya Y, Sugihara K, Akasu T, Fujita S. Nerve-sparing surgery with lateral node dissection for advanced lower rectal cancer. Eur J Cancer 1995;31A:1229-32.

14. Akiyoshi T, Ueno M, Matsueda K, Konishi T, Fujimoto Y, Nagaya- ma S, et al. Selective lateral pelvic lymph node dissection in patients with advanced low rectal cancer treated with preoperative chemoradiotherapy based on pretreatment imaging. Ann Surg Oncol 2014;21:189-96.

15. Yano H, Moran BJ. The incidence of lateral pelvic side-wall nodal involvement in low rectal cancer may be similar in Japan and the West. Br J Surg 2008;95:33-49.

16. Watanabe T, Muro K, Ajioka Y, Hashiguchi Y, Ito Y, Saito Y, et al. Japanese Society for Cancer of the Colon and Rectum (JSCCR) guidelines 2016 for the treatment of colorectal cancer. Int J Clin Oncol 2018;23:1-34.

17. Akiyoshi T, Matsueda K, Hiratsuka M, Unno T, Nagata J, Nagasa$\mathrm{ki} \mathrm{T}$, et al. Indications for lateral pelvic lymph node dissection based on magnetic resonance imaging before and after preoperative chemoradiotherapy in patients with advanced low-rectal cancer. Ann Surg Oncol 2015;22 Suppl 3:S614-20.

18. Ogawa S, Hida J, Ike H, Kinugasa T, Ota M, Shinto E, et al. Selection of lymph node-positive cases based on perirectal and lateral pelvic lymph nodes using magnetic resonance imaging: study of the Japanese society for cancer of the colon and rectum. Ann Surg Oncol 2016;23:1187-94.

19. Ogawa S, Itabashi M, Hirosawa T, Hashimoto T, Bamba Y, Kameoka S. Lateral pelvic lymph node dissection can be omitted in lower rectal cancer in which the longest lateral pelvic and perirectal lymph node is less than $5 \mathrm{~mm}$ on MRI. J Surg Oncol 2014; 109:227-33.

20. Ishihara S, Kawai K, Tanaka T, Kiyomatsu T, Hata K, Nozawa H, et al. Oncological outcomes of lateral pelvic lymph node metastasis in rectal cancer treated with preoperative chemoradiotherapy. Dis Colon Rectum 2017;60:469-76.

21. Ogawa S, Hida J, Ike H, Kinugasa T, Ota M, Shinto E, et al. The important risk factor for lateral pelvic lymph node metastasis of lower rectal cancer is node-positive status on magnetic resonance imaging: study of the Lymph Node Committee of Japanese Society for Cancer of the Colon and Rectum. Int J Colorectal Dis 2016;31:1719-28.

22. Oh HK, Kang SB, Lee SM, Lee SY, Ihn MH, Kim DW, et al. Neoadjuvant chemoradiotherapy affects the indications for lateral pelvic node dissection in $\mathrm{mid} /$ low rectal cancer with clinically suspected lateral node involvement: a multicenter retrospective cohort study. Ann Surg Oncol 2014;21:2280-7.

23. Kim MJ, Chan Park S, Kim TH, Kim DY, Kim SY, Baek JY, et al. Is lateral pelvic node dissection necessary after preoperative chemoradiotherapy for rectal cancer patients with initially suspected lateral pelvic node? Surgery 2016;160:366-76.

24. Hojo K, Sawada T, Moriya Y. An analysis of survival and voiding, sexual function after wide iliopelvic lymphadenectomy in patients with carcinoma of the rectum, compared with conventional lymphadenectomy. Dis Colon Rectum 1989;32:128-33.

25. Matsuoka N, Moriya Y, Akasu T, Fujita S. Long-term outcome of urinary function after extended lymphadenectomy in patients with distal rectal cancer. Eur J Surg Oncol 2001;27:165-9. 
26. Col C, Hasdemir O, Yalcin E, Guzel H, Tunc G, Bilgen K, et al. The assessment of urinary function following extended lymph node dissection for colorectal cancer. Eur J Surg Oncol 2005;31: 237-41.

27. Kyo K, Sameshima S, Takahashi M, Furugori T, Sawada T. Impact of autonomic nerve preservation and lateral node dissection on male urogenital function after total mesorectal excision for lower rectal cancer. World J Surg 2006;30:1014-9.

28. Maeda K, Maruta M, Utsumi T, Sato H, Toyama K, Matsuoka H. Bladder and male sexual functions after autonomic nerve-sparing TME with or without lateral node dissection for rectal cancer. Tech Coloproctol 2003;7:29-33.

29. Akasu T, Sugihara K, Moriya Y. Male urinary and sexual functions after mesorectal excision alone or in combination with extended lateral pelvic lymph node dissection for rectal cancer. Ann Surg Oncol 2009;16:2779-86.

30. Sugihara K, Moriya Y, Akasu T, Fujita S. Pelvic autonomic nerve preservation for patients with rectal carcinoma. Oncologic and functional outcome. Cancer 1996;78:1871-80.

31. Saito S, Fujita S, Mizusawa J, Kanemitsu Y, Saito N, Kinugasa Y, et al. Male sexual dysfunction after rectal cancer surgery: results of a randomized trial comparing mesorectal excision with and without lateral lymph node dissection for patients with lower rectal cancer: Japan Clinical Oncology Group Study JCOG0212. Eur J Surg Oncol 2016;42:1851-8.

32. Ito M, Kobayashi A, Fujita S, Mizusawa J, Kanemitsu Y, Kinugasa Y, et al. Urinary dysfunction after rectal cancer surgery: results from a randomized trial comparing mesorectal excision with and without lateral lymph node dissection for clinical stage II or III lower rectal cancer (Japan Clinical Oncology Group Study, JCOG0212). Eur J Surg Oncol 2018;44:463-8.

33. Konishi T, Kuroyanagi H, Oya M, Ueno M, Fujimoto Y, Akiyoshi T, et al. Multimedia article. Lateral lymph node dissection with preoperative chemoradiation for locally advanced lower rectal cancer through a laparoscopic approach. Surg Endosc 2011;25: 2358-9.

34. Park JS, Choi GS, Lim KH, Jang YS, Kim HJ, Park SY, et al. Laparoscopic extended lateral pelvic node dissection following total mesorectal excision for advanced rectal cancer: initial clinical experience. Surg Endosc 2011;25:3322-9.
35. Furuhata T, Okita K, Nishidate T, Ito T, Yamaguchi H, Ueki T, et al. Clinical feasibility of laparoscopic lateral pelvic lymph node dissection following total mesorectal excision for advanced rectal cancer. Surg Today 2015;45:310-4.

36. Ogura A, Akiyoshi T, Nagasaki T, Konishi T, Fujimoto Y, Nagayama S, et al. Feasibility of laparoscopic total mesorectal excision with extended lateral pelvic lymph node dissection for advanced lower rectal cancer after preoperative chemoradiotherapy. World J Surg 2017;41:868-75.

37. Yamaguchi T, Konishi T, Kinugasa Y, Yamamoto S, Akiyoshi T, Okamura R, et al. Laparoscopic versus open lateral lymph node dissection for locally advanced low rectal cancer: a subgroup analysis of a large multicenter cohort study in Japan. Dis Colon Rectum 2017;60:954-64.

38. Nagayoshi K, Ueki T, Manabe T, Moriyama T, Yanai K, Oda Y, et al. Laparoscopic lateral pelvic lymph node dissection is achievable and offers advantages as a minimally invasive surgery over the open approach. Surg Endosc 2016;30:1938-47.

39. Akiyoshi T, Nagata J, Nagasaki T, Konishi T, Fujimoto Y, Nagayama S, et al. Laparoscopic salvage lateral pelvic lymph node dissection for locally recurrent rectal cancer. Colorectal Dis 2015;17: O213-6.

40. Kagawa H, Kinugasa Y, Shiomi A, Yamaguchi T, Tsukamoto S, Tomioka $\mathrm{H}$, et al. Robotic-assisted lateral lymph node dissection for lower rectal cancer: short-term outcomes in 50 consecutive patients. Surg Endosc 2015;29:995-1000.

41. Yamaguchi T, Kinugasa Y, Shiomi A, Kagawa H, Yamakawa Y, Furutani A, et al. Oncological outcomes of robotic-assisted laparoscopic versus open lateral lymph node dissection for locally advanced low rectal cancer. Surg Endosc 2018;32:4498-505.

42. Shin US, Nancy You Y, Nguyen AT, Bednarski BK, Messick C, Maru DM, et al. Oncologic outcomes of extended robotic resection for rectal cancer. Ann Surg Oncol 2016;23:2249-57.

43. Shiomi A, Kinugasa Y, Yamaguchi T, Tomioka H, Kagawa H. Robot-assisted rectal cancer surgery: short-term outcomes for 113 consecutive patients. Int J Colorectal Dis 2014;29:1105-11.

44. Yamaguchi T, Kinugasa Y, Shiomi A, Tomioka H, Kagawa H. Robotic-assisted laparoscopic versus open lateral lymph node dissection for advanced lower rectal cancer. Surg Endosc 2016;30: 721-8. 